\title{
Single-use versus reusable flexible ureteroscopes: a comprehensive cost-analysis decision model
}

\author{
Ureteroscópio flexível reutilizável versus de uso único: análise de \\ custo para modelo de decisão
}

\author{
Giovanni Scala Marchini ${ }^{1,2}$, Fábio César Miranda Torricellii, ${ }^{1,2}$ Manoj Monga ${ }^{1,2}$, \\ Carlos Alfredo Batagello ${ }^{1,2}$, Fábio Carvalho Vicentini ${ }^{1}$, Alexandre Danilovic ${ }^{1}$, \\ Miguel Srougi ${ }^{1}$, William Carlos Nahas ${ }^{1}$, Eduardo Mazzucchi $^{1}$
}

\begin{abstract}
Marchini GS, Torricelli FC, Monga M, Batagello CA, Vicentini FC, Danilovic A, Srougi M, Nahas WC, Mazzucchi E. Single-use versus reusable flexible ureteroscopes: a comprehensive cost-analysis decision model / Ureteroscópio flexível reutilizável versus de uso único: análise de custo para modelo de decisão. Rev Med (Sao Paulo). 2018 May-June;97(3):323-33.
\end{abstract}

\begin{abstract}
Purpose: The significant improvements in flexible ureterorenoscopes have made flexible ureteroscopy the main treatment modality to target upper urinary pathologies. The purpose of this study was to critically evaluate all literature concerning the cost-effectiveness of flexible ureteroscopy comparing single-use with reusable scopes. Methods: A systematic online literature review was performed in PubMed, Embase and Google Scholar databases. Two separate urologists (GSM and FCT) performed the online search and reviewed all papers considered suitable and relevant for this analysis. Because of the paucity of high quality publications, not only prospective assessments but also case control and case series studies were included in the final analysis. All factors potentially affecting surgical costs or clinical outcomes were considered in the analysis. Results: 741 studies with the previously elected terms were found. Of those, 18 were duplicated and 77 were not related to urology procedures and were excluded. Of the remaining 646 studies, 59 published between 2000 and 2018 were considered of relevance to the pre-defined queries and were selected for further analysis. Stone free and complication rates were similar between single-use and reusable scopes. In special, urinary tract infection rate following flexible ureteroscopy is not inferior if a
\end{abstract}

single-use device is used instead of a reusable scope. Operative time was in average $20 \%$ shorter if a digital scope was used, single-use or not. There is a suggestion that the learning curve is shorter with single-use devices but this is not consistent in the literature. Surgeon expertise impacts the longevity of the flexible scope. Reusable digital scopes seem to last longer than optic ones, though scope longevity is very variable worldwide. New scopes usually last three to four times more than refurbished ones and single-use ureterorenoscopes have good resilience throughout long cases. Both sterilization method and cleaning process impact scope longevity, the best results being achieved with Cidex and a dedicated nurse to take care of the sterilization process. The main factors that negatively impact device longevity regarding patient and disease are lower pole pathologies, large stone burden and non-use of a ureteral access sheath. Conclusions: The costeffectiveness of a flexible ureteroscopy program is dependent of several aspects that must be considered when deciding whether to choose between a single-use and a reusable ureterorenoscope. Disposable devices are already a reality and will progressively become the standard as manufacturing price falls significantly.

Keywords: Ureteroscopy; Ureteroscopy/instrumentation; Nephrolithiasis; Cost-benefit analysis; Equipment reuse/economy; Recycling/economy.

1. Setor de Endourologia e Litíase Renal, Divisão de Urologia, Hospital das Clínicas HCFMUSP, Faculdade de Medicina, Universidade de Sao Paulo, Sao Paulo, SP, BR.

2. Glickman Urological and Kidney Institute, Cleveland Clinic, Cleveland, Ohio.

ORCID: Marchini GS - https://orcid.org/0000-0003-4334-9803; FC Torricelli - https://orcid.org/0000-0002-5845-0894; A Danilovic - https://orcid.org/0000-0002-6963-6117; M Srougi - https://orcid.org/0000-0002-4545-0596; WC Nahas - https://orcid.org/0000-00027395-8370; E Mazzucchi - https://orcid.org/0000-0003-3870-5922.

Corresponding author: Giovanni Scala Marchini. Section of Endourology, Division of Urology, Hospital das Clínicas, University of Sao Paulo Medical School, Sao Paulo, SP, Brazil. Av. Dr. Enéas Carvalho de Aguiar, 255. Cerqueira César, São Paulo, SP, BR. CEP: 05403-900. Email: marchinism@gmail.com. 
RESUMO: Objetivo: As melhorias significativas nos ureterorrenoscópios flexíveis tornaram a ureteroscopia flexível a principal modalidade de tratamento para as patologias de trato urinário superior. $\mathrm{O}$ objetivo deste estudo foi avaliar criticamente toda a literatura sobre a custo-efetividade da ureteroscopia flexível comparando aparelhos de uso único com reutilizáveis. Métodos: Uma revisão sistemática da literatura online foi realizada nas bases de dados PubMed, Embase e Google Scholar. Dois urologistas distintos (GSM e FCT) realizaram a pesquisa online e revisaram todos os trabalhos considerados adequados e relevantes para esta análise. Devido à escassez de publicações de alta qualidade, não apenas as avaliações prospectivas, mas também os estudos de casos e séries de casos foram incluídos na análise final. Todos os fatores que potencialmente afetam os custos cirúrgicos ou os desfechos clínicos foram considerados na análise. Resultados: foram encontrados 741 estudos com os termos previamente eleitos. Destes, 18 eram duplicados e 77 não tinham relação com procedimentos de urologia e foram excluídos. Dos restantes 646 estudos, 59 publicados entre 2000 e 2018 foram considerados relevantes para as consultas pré-definidas e foram selecionados para análise posterior. As taxas de complicações e livres de cálculo foram semelhantes entre os escopos de uso único e reutilizáveis. Em especial, a taxa de infecção do trato urinário após ureteroscopia flexível não é inferior se um dispositivo de uso único for usado em vez de um reutilizável. O tempo cirúrgico foi em média $20 \%$ menor se um ureteroscópio digital

\section{INTRODUCTION}

$\mathrm{T}$ he significant improvements in flexible ureterorenoscopes have made flexible ureteroscopy the main treatment modality to target upper urinary pathologies, especially stone disease ${ }^{1-4}$. The low invasiveness of the procedure has made it popular worldwide as an effective alternative to shock wave lithotripsy and percutaneous nephrolithotomy ${ }^{2-4}$. Nevertheless, there is growing concern globally regarding its high costs.

Flexible ureterorenoscopes are expensive to acquire and have limited longevity ${ }^{5}$. Also, one must consider the costs of the laser machine used for stone fragmentation, personnel to take care of cleaning and sterilization processes, and all the disposable instruments used within the flexible ureteroscope procedure which have made it so efficient. Finally, when a reusable scope breaks, most institutions experience a long delay for its replacement or repair, obligating to have more than one device so that the surgical program is not suddenly interrupted.

To counterbalance that scenario, we are now entering in the era of single-use flexible scopes ${ }^{6,7}$. In principle, the disposable ureterorenoscope eliminates the high costs of reusable scopes purchase and repair. It also abolishes the theoretical risk of cross infections and also the need for a sterilization process. Finally, some advocate that the disposable scope allows more torque in the instrument during a stone treatment procedure without the fear of breakage, pushing flexible ureteroscopy boundaries even more.

The purpose of this study was to critically evaluate foi usado, seja de uso único ou não. Há uma sugestão de que a curva de aprendizado é mais curta com dispositivos de uso único, mas isso não é consistente na literatura. A experiência do cirurgião afeta a longevidade do aparelho flexível. Os aparelhos digitais reutilizáveis parecem durar mais que os ópticos, embora a longevidade seja muito variável em todo o mundo. Os novos ureteroscópios costumam durar de três a quatro vezes mais do que os recondicionados e os ureterorrenoscópios de uso único apresentam boa resiliência em casos longos. Tanto o método de esterilização como o processo de limpeza impactam a longevidade do aparelho, sendo os melhores resultados alcançados com o Cidex e uma enfermeira dedicada para cuidar do processo de esterilização. Os principais fatores que impactam negativamente a longevidade do dispositivo em relação ao paciente e à doença são patologias do polo inferior, grande volume de cálculo e não uso de uma bainha de acesso ureteral. Conclusões: A relação custo-efetividade de um programa de ureteroscopia flexível é dependente de vários aspectos que devem ser considerados ao se decidir se deve escolher entre ureterorrenoscópio de uso único e reutilizável. Os dispositivos descartáveis já são uma realidade e se tornarão progressivamente o padrão a partir do momento que o preço de fabricação cair significativamente.

Descritores: Ureteroscopia; Ureterosocopia/instrumentação; Nefrolitíase; Análise custo-benefício; Reutilização de equipamento/encômia; Reciclagem/econômia.

all literature concerning the cost-effectiveness of flexible ureteroscopy comparing single-use with reusable scopes. We aimed to answer queries specifically formulated to elucidate which is the most suitable device for every specific institution.

\section{METHODS}

\section{Literature review}

A systematic online literature review was performed in PubMed, Embase and Google Scholar databases. The following keywords were used to attain relevant studies regarding flexible ureteroscopy using reusable and disposable scopes: "flexible" combined with the urological terms "ureteroscopy", "ureteroscope", "ureterorenoscopy", "ureteroscopic", "ureteropyeloscopy", "durability", "longevity", "cost-analysis", "digital", "fiber-optic", "single-use", "disposable", "reusable", "renal”, "urinary" and "sterilization".

No institutional review board was required since the study design is a systematic review. All the relevant studies were gathered, organized, and brought to discussion. Two separate urologists (GSM and FCT) performed the online search and reviewed all papers considered suitable and relevant for this analysis. Because of the paucity of high quality publications, not only prospective assessments but also case control and case series studies were included in the final analysis. If data was unclear or incomplete, the corresponding author was contacted to provide the required data. 


\section{Theme analysis and eligibility criteria}

We performed the review of all published studies on flexible ureteroscopy in order to establish a literature-based decision model for flexible ureteroscope acquisition. For that, we aimed to answer pre-defined questions formulated by two experienced endourologists (GSM and FCT) who work on private and public institutions with different medical reimbursement policies and surgical material supplies used for endourological procedures. These queries were designed to evaluate the clinical and economic impact of the type of flexible ureteroscope used on daily practice. All factors potentially affecting surgical costs or clinical outcomes were considered in the analysis. The list of questions is described on Table 1.

Table 1 - Pre-defined questions regarding flexible ureteroscopy and rationale

\begin{tabular}{c|l}
\hline 1$)$ & $\begin{array}{l}\text { Are the stone free and complication rates different } \\
\text { between single-use and reusable flexible ureteroscopes? }\end{array}$ \\
\hline 2$)$ & $\begin{array}{l}\text { Is the operative time different between single-use and } \\
\text { reusable flexible ureteroscopes? }\end{array}$ \\
\hline 3$)$ & $\begin{array}{l}\text { Does surgeon experience impact clinical and economic } \\
\text { outcomes in a individualized manner between single-use } \\
\text { and reusable scopes? }\end{array}$ \\
\hline 4$)$ & $\begin{array}{l}\text { Is the longevity of digital and optical flexible } \\
\text { ureteroscopes different? Also, is it different between } \\
\text { new and refurbished scopes? }\end{array}$ \\
\hline 5$)$ & $\begin{array}{l}\text { Does the sterilization method influences permanent } \\
\text { scope longevity? }\end{array}$ \\
\hline 6$)$ & $\begin{array}{l}\text { What is the impact of stone burden and surgical } \\
\text { instrumentation on ureteroscope longevity? }\end{array}$ \\
\hline
\end{tabular}

\section{RESULTS}

After extensive review of the literature, 741 studies with the previously elected terms were found (Figure 1). Of those, 18 were duplicated and 77 were not related to urology procedures and were excluded. Of the remaining 646 studies, 59 published between 2000 and 2018 were considered of relevance to the pre-defined queries and were selected for further analysis. The studies consisted of four randomized controlled trial $1^{9,11,38,56}$, three multicenter trials ${ }^{17,30,33}, 40$ case series s, $8,10,12,13,15,16,25-29,31,32,34-37,39,41,42,44-52,54,55,57-63,66$, one cadaveric feasibility study ${ }^{18}$, one animal feasibility study ${ }^{19}$, and ten bench top studies ${ }^{14,20-24,40,53,64,65}$.

Reusable scopes included were fiber optic Olympus URF-P3 14,26,30,39,43,48,55,56,62,66, fiber optic Olympus URF-P5 ${ }^{5,9,18,19,33,44,46,54,61}$, fiber optic Olympus URF-P6 ${ }^{10,13,49}$, fiber optic Karl Storz Flex-X ${ }^{14,30-32,39-41,50,59}$, fiber optic Karl Storz Flex-X² 11,28,35,45,47,57,58,60,61, fiber optic ACMI DUR-8 and DUR-8 elite ${ }^{14,29,30,33,36,37,39,59}$, fiber optic Richard Wolf $7330 / 1^{14,26,30,39,63,64}$, fiber optic Richard Wolf Cobra ${ }^{20,24}$, fiber optic Richard Wolf Viper ${ }^{33}$, fiber optic ACMI AUR-726, fiber optic Stryker Flex Vision U-500 $0^{33}$, digital Olympus
URF-V $5,18,27,28,51,52$, digital ACMI/Olympus DUR-D (38), digital Karl Storz Flex-X $X^{\mathrm{C} 11,20,24,25,28,35,42}$. Single-use flexible ureteroscopes included were LithoVue ${ }^{\mathrm{TM} 10,11,13,20,22-24,42,51,52}$, Polyscope ${ }^{\mathrm{TM} 8,9,15,16,21,34}$, SemiFlex $^{\mathrm{TM} 14}$, Pulsen $^{\mathrm{TM} 23}$, YouCare Tech YC-FR-A ${ }^{\mathrm{TM} 24}$, Neoscope NeoFlex ${ }^{\mathrm{TM} 24}$.

The experts who carefully selected all studies discussed the articulated questions and formulated literature-based answers.

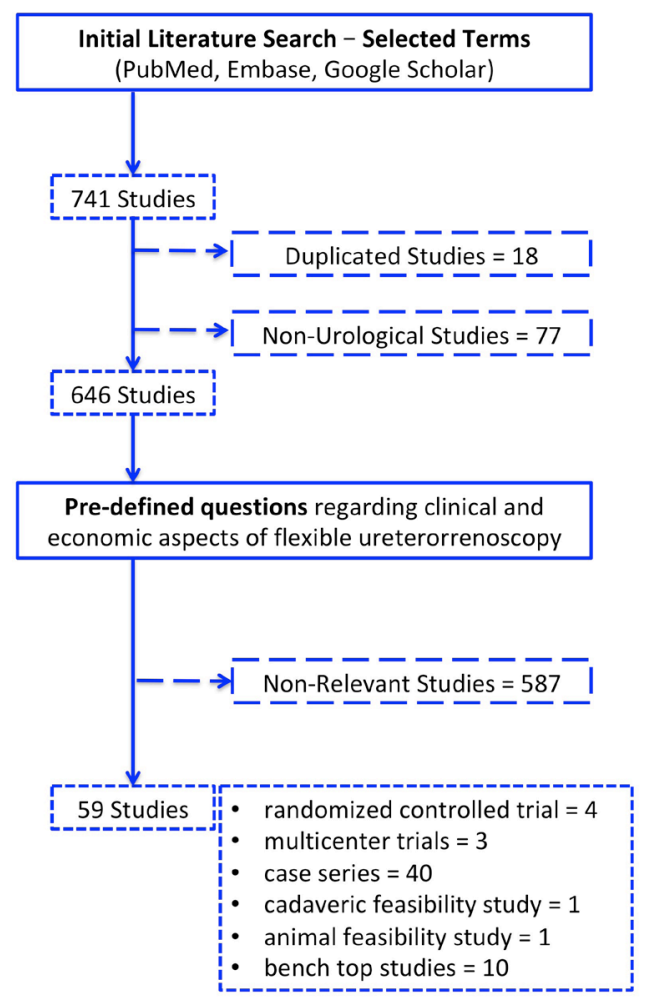

Figure 1. Study selection algorithm

\section{Stone free and complication rates}

Somani et al. ${ }^{5}$ published a study comparing reusable digital versus fiber optic flexible ureteroscopes and the results were similar in terms of accessibility to the entire collecting system and stone-free rates (SFRs). Complication rates were similar between the two modalities. Nevertheless, the authors did not use disposable scopes and single-use digital scopes are not exactly similar to the reusable digital instruments.

The Polyscope ${ }^{\mathrm{TM}}$ has been introduced in urologic armamentarium as a modular, semi disposable flexible ureterorenoscope system ${ }^{8}$. One study prospectively compared clinical outcomes of the Polyscope ${ }^{\mathrm{TM}}$ with reusable Olympus fiberoptic URF-P5 scope9. After including 180 patients in each arm, the mean stone size for single-use and reusable scopes was $1.36 \pm 0.2$ versus $1.34 \pm$ $0.18 \mathrm{~cm}(\mathrm{p}=0.93)$. The single session SFR postoperatively 
for Polyscope ${ }^{\mathrm{TM}}$ and URF-P5 was $76.7 \%$ versus $69.4 \%$ $(\mathrm{p}=0.12)$, respectively. However, for lower calyceal stones, URF P-5 was significantly better than Polyscope ${ }^{\mathrm{TM}}$ providing a SFR of $82.0 \%$ versus $69.2 \%(\mathrm{p}=0.022)$, respectively. The complication rate was $15.3 \%$ versus $15 \%$ $(p=0.3)$, respectively. Urosepsis occurred in $5 \%$ of patients in the Polyscope ${ }^{\mathrm{TM}}$ group and $3.3 \%$ in the reusable scope cohort $(p=0.42)$. Single-use devices performed well and the findings suggest that new disposable scopes are noninferior to reusable scopes in terms of clinical outcomes.

Usawachintachit et al. ${ }^{10}$ performed a more recent prospective case-control study in which LithoVue ${ }^{\mathrm{TM}}$ (Boston Scientific, Marlborough, MA, USA) was compared to Olympus fiberoptic URF-P6. A total of 116 cases were performed with single-use scope and 65 cases with reusable scopes. The number of patients with complete SFR (no fragments), insignificant residual fragments $(\leq 2 \mathrm{~mm})$ and significant fragments $(>2 \mathrm{~mm})$ was $60.0 \%, 12.5 \%, 27.5 \%$ for LithoVue ${ }^{\mathrm{TM}}$, and 44.7\%, 13.2\%, 42.1\% for URF-P6 $(p=0.36)$, with a tendency towards better outcomes with the single-use scope. Mager et al. ${ }^{11}$ prospectively compared 68 consecutive procedures using reusable flexible ureterorenoscopes (Flex-X2 $2^{\mathrm{S}} /$ Flex-X $^{\mathrm{C}}$, Karl Storz, Tuttlingen, Germany) with 68 consecutive procedures utilizing single-use digital flexible ureterorenoscopes (LithoVue ${ }^{\mathrm{TM}}$ ). Patients had same stone burden and demographic characteristics. The authors found nonsignificant different stone free $(82 \%$ vs. $85 \% ; p=0.8)$ and complication rates ( 7 vs. $17 \%$; $p=0.06$ ) with reusable and single use scopes, respectively. In the single-use group, complications classified as Clavien-Dindo II $(n=2 ; 3 \%)$ were caused by febrile urinary tract infection and by the necessity for additional anticonvulsive therapy in a young patient with cerebral palsy. No urinary tract infections occurred in the reusable scope cohort.

Regarding perioperative complications, urinary tract infection (UTI) remains a feared hurdle following ureteroscopy. It is potentially related to previous double $\mathrm{J}$ use and specially dreaded if the flexible scope is sterilized on Cidex or other solutions. A study in France reports that acute pyelonephritis is a rare complication of ureteroscopy $(2.4 \%)^{12}$. In the study by Usawachintachit et al. ${ }^{10}$, perioperative complications were found in 14 cases and mostly categorized as Clavien-Dindo grade I or II. The complication rate was lower in the LithoVue ${ }^{\mathrm{TM}}$ group compared to the URF-P6 group (5.4\% versus $18.0 \%$, $\mathrm{p}<0.05)$. Interestingly, there were three cases of UTI in each arm. Similar rates of UTIs were seen in other studies comparing single-use with reusable scopes ${ }^{9,11}$.

\section{Operative time}

One study prospectively comparing the Polyscope $\mathrm{PM}^{\mathrm{TM}}$ single-use flexible ureteroscope with reusable scopes found similar mean procedure duration: $73 \pm 27$ versus $74 \pm 13$ $\min (p=0.99)$, respectively ${ }^{9}$. In this study, both types of flexible ureteroscopes, disposable and permanent, were fiberoptic.

In the study by Somani et al. ${ }^{5}$, the authors found that the digital flexible scope allowed a decreased operative time by $20 \%$ with similar SFR. In the study by Usawachintachit et al. ${ }^{10}$, the overall mean procedure duration was 10.4 minutes shorter for LithoVue ${ }^{\mathrm{TM}}$ than with fiberoptic URF-P6 (64.5min vs. $54.1 \mathrm{~min}, \mathrm{p}<0.05)$. This difference broadened to 13 minutes and remained statistically significant in cases performed for stone removal (70.3 vs. $57.3 \mathrm{~min}, \mathrm{p}<0.05$ ). This was translated in shortened operating room duration in stone removal cases with LithoVue ${ }^{\mathrm{TM}}$ (104.3min vs 89.8 min, respectively, $\mathrm{p}<0.05$ ).

In a subsequent study from the same group, Tagushi et al. ${ }^{13}$ prospectively compared flexible ureteroscopy with the fiberoptic Olympus URF-P6 and LithoVue ${ }^{\mathrm{TM}}$ in a micro-cost analysis. They found a non-significant $19.8 \mathrm{~min}(93.4 \mathrm{~min}$ vs. $73.6 \mathrm{~min} ; \mathrm{p}=0.09)$ or $21 \%$ shorter total operative with the digital single-use scope. This was translated in a mean reduction from US\$ $1,618.72$ to US\$ 1,348.64 per procedure. In the study by Mager et al. ${ }^{11}$, the author compared permanent digital (Storz Flex-X ${ }^{\mathrm{C}}$ ) with single-use LithoVue ${ }^{\mathrm{TM}}$ and found similar operative time (76.2 vs. $76.8 \mathrm{~min} ; \mathrm{p}=0.9$ ).

\section{Surgical expertise impact on ureteroscope efficiency}

Several studies have evaluated the mechanical, optical and irrigation properties of single-use ureterorenoscopes in bench simulations, cadaveric

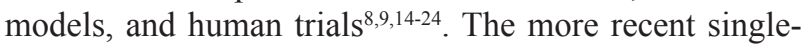
use scopes have good performance and do not lack in endurance and maneuverability compared to permanent equipment. However, literature lacks of a comprehensive learning-curve analysis and most surgeons who shifted to single-use scopes had prior training with permanent flexible ureteroscopes.

A recent multi-institutional, prospective, comparative study by Usawachintachit et al. ${ }^{10}$ paralleled procedural outcomes between LithoVue ${ }^{\mathrm{TM}}$ and reusable ureteroscopes. The authors found that the LithoVue ${ }^{\mathrm{TM}}$ was associated with a shorter learning curve and had comparable procedural outcomes and complication rates when matched with reusable flexible optical ureteroscopes. Nevertheless, no dedicated learning-curve investigation was performed and the fact that a digital scope was compared to a fiberoptic one might explain the results.

There are no studies comparing scope longevity in regards to single surgeon versus multiple surgeons use. However, a recent case series of flexible ureteroscopy using the Storz digital Flex- $\mathrm{X}^{\mathrm{C}}$ by a single expert urologist with more than 1000 flexible ureteroscopies performed in the past and previous experience with this particular endoscope model has shown long scope longevity with a single scope lasting 159 cases $^{25}$. 
Longevity of digital, optical, new and refurbished flexible ureteroscopes

Some authors report that, in average, a digital ureteroscope is used 21 times before requiring repair, while the average fiberoptic ureteroscope is only used 6 to 15 times before going back to the manufacturer ${ }^{26,27}$. In a recent study by Legemate et al. ${ }^{23}$, permanent digital scopes had a slightly longer longevity (mean 27 cases; 20-56) compared to fiber optic flexible ureteroscopes (mean 24 cases; 10-37). However, a wider look at all published literature reveal that new flexible scopes may last as long as 5 to 159 cases $^{25-52}$. In comparison, the average longevity of refurbished flexible scopes ranges from 3 to 11 cases $^{35-39}$. In addition, one study suggests that not only brand-new flexible ureteroscopes are more resistant to damage (mean of 44 usages in this specific trial) than devices refurbished, but that scopes last more if they are repaired by original manufacturer (mean 11.1 cases) than by outsourced vendors (mean 6.9 cases) ${ }^{36}$. This should be acknowledged when deciding whether to repair an old scope or buy a new one.

In modern series with single-use flexible scopes, the resilience of the equipment was proved to be adequate even for long cases ${ }^{9,10,13,16}$. In the European prospective multicentric clinical study by Doizi et al. ${ }^{17}$, however, there were two failures with LithoVue ${ }^{\mathrm{TM}}(5 \%)$, which demanded the surgeons to use the permanent scope to finish the case.

\section{Sterilization method impact on scope longevity}

Different series investigating flexible ureteroscope breakage report that it may occur outside of the operating room, during processing and storage in 7.7 to $22 \%$ of times, even in the hands of experienced and dedicated staff ${ }^{26,29}$.

Abraham et al. ${ }^{40}$ studied two identical fiber optic ureteroscopes that underwent two different sterilization processes: Steris 1 (peroxyacetic acid 35\%; 30min cycle at $50^{\circ}$ to $56^{\circ} \mathrm{C}$ ) and Cidex OPA (Johnson and Johnson Co., Irvine, CA; glutaraldehyde $2.4 \% ; 30$ to $40 \mathrm{~min}$ soak cycle at room temperature followed by a rinse in sterile water). The authors have demonstrated that after 100 cycles, the first ureteroscope, which was sterilized in the Steris system, had a $12 \mathrm{~mm}$ tear on its shaft, 297 damaged fibers, and a 37\% drop in resolution. Conversely, the second ureteroscope, which was sterilized with Cidex, had no visible external damage and had only 10 damaged fibers.

In a clinical trial by McDougall et al. ${ }^{48}$, a new Olympus URF-P3 flexible ureteroscope was used for two 30-day independent study periods during which a single surgeon used the endoscope for a variety of upper urinary tract procedures. During the first 30-day period, the endoscope was cleaned by the endourology support team using the Steris $20(\mathrm{n}=11$ cases; total procedure time of $457 \mathrm{~min}$ ). During the second 30 -day period, a separate endoscope was cleaned only by the surgeon using the
Cidex technique ( $\mathrm{n}=15$ cases; operative time of $618 \mathrm{~min}$ ). In follow-up evaluation of the flexible ureteroscopes, there was no change in the angle of flexion or deflection in either group during the study period and leak-proof-pressure testing was acceptable in both endoscopes. In Steris group, no optical fibers were noted to break during use. In Cidex group, during the study, eight fibers were broken. These findings are in discordance with the study by Abraham et al. ${ }^{40}$. Still, the authors believe this was specifically related to a higher prevalence of lower pole stone location in the Cidex cohort and not to the sterilization process itself.

When we look at scope longevity, series that report longer scope duration are in general those where they were sterilized on Cidex and not Steris. Carey et al. ${ }^{29}$ report new scope duration of at least 48 cases using Cidex method. Delfidio et al. ${ }^{32}$ report fiberoptic ureteroscope duration of more than 100 cases for two scopes with the same process. Multescu et al. ${ }^{25}$ achieved the noteworthy mark of 159 procedures with a single digital Storz Flex-Xc. On the other hand, in a recent series by Mager et al. ${ }^{11}$ where Steris was the sterilization method, in 68 procedures utilizing reusable flexible ureterorenoscopes (Flex- $\mathrm{X}^{\mathrm{C}}$ and Flex$\mathrm{X} 2^{\mathrm{S}}$ ), 9 repair orders were needed caused by 5 damages of brand new and 4 damages of used instruments. In the study by Semins et al. ${ }^{45}$, after all urology nurses had been educated by the charge nurse of the urology service as to the proper endoscope cleaning, processing, and sterilizing protocols with Steris system, the average number of uses per ureteroscope before repair was necessary increased from 10.8 to 28.1 , with a repair cost saving of US\$ 300,00 per use.

\section{Impact of stone burden and surgical instrumentation on ureteroscope longevity}

Several surgical and patient factors might affect stone free rates, morbidity and also ureteroscope longevity. In addition, some aspects of the surgeon technique, such as the inadvertent firing of a laser inside the working channel of the scope, lower pole stone relocation, and use of a ureteral sheath can affect the longevity of an ureteroscope ${ }^{45}$.

Access sheaths have been shown to protect the kidney and the ureter during flexible ureteroscopy and to potentially increase $\mathrm{SFR}^{53}$. A large retrospective cohort confirmed the safety of the ureteral access sheath but failed to show any improvement in the stone free status among patients with compared to those in which the access sheath was not used ${ }^{54}$. Pietrow et al. ${ }^{55}$ have reported that the routine use of ureteral access sheaths, miniaturized nitinol baskets and smaller laser fibers will minimize the strain placed on a ureteroscope during a procedure, ultimately increasing the flexible ureteroscope longevity. Other investigators have also suggested that the routine use of a ureteral access sheath may also help to improve the durability of the flexible ureteroscope since it provides continuous ureteral 
access, reduced ureteral trauma, and shorter operative times ${ }^{56}$. Multescu et al..$^{25}$ advocate routine use of an ureteral access sheath and have recently published a case series using three new generation digital flexible ureteroscopes in which they lasted for 96, 151 and 159 cases. However, to date, there are no well-designed prospective randomized trials to provide strong evidence that the durability of the deflection unit of the flexible ureteroscope is preserved using this technique.

Jacquemet et al. ${ }^{57}$ retrospectively compared the outcomes of flexible ureteroscopy for stone treatment in patients with calculi in the lower pole $(n=232)$ versus with calculi in other kidney locations $(n=139)$. Stone burden was similar between groups but stone size $<10 \mathrm{~mm}$ (61.2\% vs. $48.5 \%$; $\mathrm{p}=0.018)$ and use of an access sheath were more frequent in the lower pole cohort $(80.2 \%$ vs. $66.9 \% ; p=0.007)$. In only $19.8 \%$ of these cases the calculus was relocated to a more favorable position in the kidney. Procedure duration was similar between groups (99.4min vs. $100.9 \mathrm{~min} ; \mathrm{p}=0.76)$. Stone free rate was also similar (68.3\% in lower pole group vs. $69.8 \%$; $\mathrm{p}=0.77$ ) with no difference in regards to complication rates $(9.1 \%$ vs. $7.9 \%$, respectively; $\mathrm{p}=0.67)$. On multivariate analysis, stone size $>10 \mathrm{~mm}$ and multiple stone location were associated with treatment failure, but lower pole location was not. Jessen et al. ${ }^{58}$ retrospectively evaluated the influence of the collecting system anatomy on the efficacy and morbidity of flexible ureteroscopy and found that stone size, long infundibulum, and infundibulopelvic angle $<30^{\circ}$ negatively affected the stone free rate. Perlmutter et al..$^{59}$ retrospectively evaluated the impact of stone location on 86 cases managed by flexible ureteroscopy and laser lithotripsy and also found that stone location did not significantly affect the SFR. Martin et al. ${ }^{60}$ retrospectively compared 89 cases of flexible ureteroscopy for lower pole stones with 73 cases with stones in other locations and on multivariate analysis the presence of multiple stones was the only statistically significant predictive factor of SFR. Similar findings were reported by Resorlu et al. ${ }^{61}$, who pointed as independent factors for success the stone size, number, composition, infundibulopelvic angle and renal malformations.

The common intraoperative practice of stone displacement with a basket or grasper into the renal pelvis or upper pole for lithotripsy could explain why stone location did not have an impact on the stone free rate. Kourambas et al. ${ }^{62}$ demonstrated that the SFR for lower pole stones was slightly better if stones were relocated, though significance as not achieved probably due to the small sample size ( $90 \%$ vs. $83 \%$, respectively; $p>0.05$ ). Schuster et al. ${ }^{63}$ also obtained higher success rates with this method for lower pole stones versus lithotripsy without displacement specifically for stones $>10 \mathrm{~mm}(100 \%$ vs. $29 \% ; \mathrm{p}=0.005$ ). The criteria for stone relocation are usually the size and accessibility of the stone, the size of the basket, and surgeon expertise. If the lower pole stone is larger than the infundibulum, it may not allow repositioning and the surgeon has to perform laser lithotripsy in situ.

Although most studies support that SFR are similar for lower pole and non-lower pole stone, there is increasing evidence that there is a correlation between the technical difficulty of the procedure and a higher incidence of ureteroscope malfunction ${ }^{64}$. Bagley et al. ${ }^{65}$ have shown that a mean of $140^{\circ}$ deflection angle might be required to allow the tip of the flexible ureteroscope to reach the lower pole calyx. Auge et al. ${ }^{66}$ reported that in situ fragmentation of lower pole calculi is not possible in $28-34 \%$ of cases because of reduced ureteroscope deflection caused by the optical fiber. In those cases, potential harm to the scope occurs. In forced deflections where the laser fiber is unable to maintain total internal reflection, the photons may refract into the cladding and jacket rather than reflect back into the core fiber, with resultant fiber failure and ureteroscope damage ${ }^{30,33}$. Forbes et al. ${ }^{50}$ retrospectively analyzed laser fiber logs during flexible ureteroscopy for stone treatment and found that malfunction occurred in 8 of 142 cases (5.6\%), all with the Innova Quartz fiber and none with the Boston Flexiva fiber. Importantly, all 8 cases were in procedures for lower pole stones ( 8 of $79 ; 10.1 \%$ ) and resulted in flexible ureteroscope damage. No failure occurred with either fiber in a non-deflected configuration. The authors have demonstrated that fiber failure reflects an inability to maintain reflection and is not based on energy used or stone burden. Also, that fiber fracture at the maximal deflection results in scope damage and increases operating room time and costs.

In the study by McDougall et al. ${ }^{48}$ comparing flexible ureteroscope sterilization with Steris by the endourology support team versus with Cidex technique by the surgeon, more broken fibers ( 8 versus none) were seen in he second group during the 30-day period evaluated. The authors report that this difference was related to the fact that this second group had a higher incidence of lower pole pathology $(5 / 15$ versus $2 / 11)$ and that the majority of the procedures were for stone disease. The combination of aggressive active deflection of the flexible ureteroscope and simultaneous passage of the holmium laser probe may stress the fiberoptic system and result in fiber breakage. In a recent series by Ozimek et al. ${ }^{51}$, the authors evaluated their reusable flexible ureterorenoscopy program and found that in 32 of $423(7.5 \%)$ cases the scopes were defective after the procedures. Thirty-one of 32 cases $(96.86 \%)$ with proven scope damage were related to exploration of the lower pole and in 20 of $23(86.96 \%)$ it was for stone treatment in that location. The authors stated that a steep infundibulopelvic angle (IPA $\leq 50^{\circ}$ ) was confirmed in intraoperative retrograde pyelography in over half of the analyzed cases and that extreme flexion of the tip to reach the lower kidney pole, especially when trying to reach a ventral calyx, could play a role in the scope damage mechanism. Hennessey et al. ${ }^{52}$ treated 234 patients for renal stone procedures with seven 
new Olympus URF-V instruments and had 15 major scope damages in a 30-month period. Staghorn stones $(\mathrm{p}=0.016)$ and stones in the lower pole calyx or mid zone calyx $(\mathrm{p}=0.074)$ were significant risk factors for scope damage.

\section{Cost-analysis decision model}

The overall cost of a reusable scope must consider the financial expenditure for three main parameters: scope purchase, repair and sterilization. A recent series reported the cost of a new conventional flexible ureteroscope (Flex-X, Karl Storz, Germany) to be around US\$ 13.611 11 . The digital Olympus URF-V has been recently purchased by US\$ 20.200 in an Australian series ${ }^{52}$. The repair cost, diluted by case and scope longevity, also has a wide range in the literature from US\$ 48 to US\$ $605^{40-47,51,52}$ per case. Both purchase and repair costs may be influenced by the business contract between the owner of the scope and the manufacturer or its dealer. The reprocessing or sterilization cost includes personnel (nurses, technicians), material for brushing, leakage testing, cleaning, packaging, and sterilization. If we do not consider the value of acquisition of STERRAD machine, recent cost-analysis studies show a reprocessing cost varying from US\$ 19.9 to US\$ 108.00 per case 13,41,49,52. $^{2}$

When a disposable scope is being considered, repair should not be considered in the equation. Furthermore, there is no reprocessing and this should be exchanged for recycling and labor. Tagushi et al. ${ }^{13}$ have shown a US\$ 3.65 recycling cost per scope used. The main factor being considered for the single-use scope is always the purchase cost. This is mainly influenced by the generation of the disposable scope and by the business contract with the manufacturer. Recent purchase prices reported for the existing scopes are US\$ 1300 to US\$ 3180 for LithoVue $\mathrm{TM}^{\mathrm{TM} 2,41,52,53}$, US\$ 700 for Polyscope $\mathrm{TM}^{\mathrm{TM} 34}$ and US\$ 800 for SemiFlex ${ }^{\mathrm{TM} 14}$.

A recent investigation by Martin et al. ${ }^{42}$ assessed the economic consequences of reusable flexible ureteroscopes by performing a cost-benefit analysis on all flexible ureteroscopies. Permanent digital Flex- $\mathrm{X}^{\mathrm{C}}$ ureteroscopes and single-use LithoVue ${ }^{\mathrm{TM}}$ were used in a total of 160 cases performed over a one-year period in which eight reusable scopes required repair. They demonstrated a cost of US\$ 848.10 per case and favored reusable ureteroscopes only after 99 procedures were performed. The authors finally suggested that high-volume institutions might find reusable ureteroscopes more cost beneficial. Mager et al. ${ }^{11}$ also made a cost-analysis study and found that cost of reusable flexible ureterorenoscopy ranged between US\$ 436 and US\$ 708 per case. When taking into consideration the initial purchasing costs, it increased to US\$ 1212 - US\$ 1743 per case. In their series, LithoVue ${ }^{\mathrm{TM}}$ had a price range of US\$ 1300 (market price) to US\$ 3180 (MSRP) per procedure. In a prediction model, after 61 to 118 cases the routine use of a disposable scope would become more expensive than the routine use of reusable scopes.

In the German case series by Ozimek et al. ${ }^{51}$, the authors performed a retrospective evaluation of 102 diagnostic flexible ureteroscopies and 321 procedures for kidney stone treatment. The average number of cases resulting in scope damage was estimated to be 14.4 and the total cost of all procedures was estimated to be US\$ 261,332. This resulted in an average cost per flexible ureteroscopy procedure of US\$ 617.4 and the authors concluded that the reusable scope program was more costeffective than if single-use scopes were employed since the assumed price per LithoVue ${ }^{\mathrm{TM}}$ device was US\$ 1,227.5.

Hennessey et al. ${ }^{52}$ found a total repair cost for the 7 new digital scopes over the 30-month time period to be US\$ 124,800 , with a mean cost per case of US\$ 533 (from US\$ 276 to US\$904). The cumulative cost of 28 cases for the reusable flexible scope was approximately US\$38,360. If the single-use scope (LithoVue ${ }^{\mathrm{TM}}$ ) was priced at US\$1,918, then it would cost approximately US\$ 55,239 for the same 28 cases and reusable scopes would be more economical. Conversely, if the single-use disposable scope was priced at US\$ 920, then the cost for 28 cases would be around US\$ 26,850 and this would represent a considerable cost saving and suggest that switching to the disposable scope would make sense from an economic point of view.

\section{DISCUSSION}

The uncertainty of choosing between a singleuse or a reusable flexible scope would not have clinical importance if the stone free rate with one was significantly superior to the achieved with the other. The first generation of disposable scopes had been tested and suboptimal surgical outcomes precluded their incorporation on daily practice $^{9,15,16}$. Polyscope ${ }^{\mathrm{TM}}$ performed adequately but was unable to provide the same SFR for lower pole stones than reusable scopes ${ }^{9}$. Newer scopes provide similar maneuverability and clinical efficacy to reusable scopes with equal low complication rates and are now part of the urology routine worldwide ${ }^{6,10,13,17,18,20,22-24,42}$. The trial by Usawachintachit et al. ${ }^{10}$ could even have shown superiority with LithoVue ${ }^{\mathrm{TM}}$ compared to a reusable scope if a larger sample size was included in the study. Low SFR with flexible ureteroscopy for stone disease means more residual fragments, more subsequent consultations, more imaging examinations, higher radiation exposure, more secondary procedures, and ultimately increased patient burden and dissatisfaction.

Higher complication rates translates into prolonged hospitalization time, need for additional surgical procedures and medical treatment. In a recent study by Ofstead et al. ${ }^{67}$ where reprocessing practices of two institutions were evaluated, some kind of contamination was found in 100\% of ureteroscopes after the sterilization process. The authors 
reinforce the need for frequent audits of reprocessing practices and highlight that the clinical implications of residual contamination and viable microbes found on sterilized ureteroscopes are still unknown. In that sense, no study has ever shown an inferior rate of urinary tract infection after flexible ureteroscopy with the employment of single-use devices ${ }^{6,7,10}$. Therefore, the initial fear of cross infection with reusable scopes is not supported by existing literature and this is only a potential benefit from single-use scopes which has yet to be proven in clinical practice. The costs involved in patients with septic and other complications were not considered in our costanalysis decision model since they are. Nevertheless, they are important and patient safety should never be forgotten.

Scope longevity with solution sterilization with Cidex seems longer than with Steris ${ }^{40}$. However, local and federal regulations should be consulted before defining the ideal cleaning and reprocessing process for each institution. If Cidex sterilization is allowed, we strongly advocate benchmark in high volume centers with very low complication rates where these processes are performed in a very strict manner ${ }^{18,31}$. Also, some investigations suggest that having a trained and dedicated staff may reduce by half the breakage rate outside the operating room ${ }^{45}$. This seems reasonable and feasible, though separating this operating room personnel from other departments might increase costs. Large centers in which sterile processing departments prepare a varied selection of instruments could potentially reduce costs compared to smaller and more specialized centers $^{49}$.

Operative time should also be accounted for when choosing the ideal scope for your institution. Shorter operative time translates into lower operating room cost. The better view of the digital scope allows the surgeon to perform a safe and effective procedure, achieving comparable SFRs of fiber-optic scopes in a shorter time period $^{10,13}$. If because of surgeon preference a ureteral access sheath is in place, this also means less time of potential ureteral ischemia to the patient. It seemed reasonable to the authors of this review that any formula to compare overall costs for both types of scopes should consider the operating time in the equation and this is unique. If a digital scope is used for this parameter, irrespective of it being singleuse or reusable, it should be preceded by a 0.8 coefficient $(-20 \%)$ as it is more efficient in terms of time. This could ultimately allow more patients to be treated in the same operating room. In addition, Isaacson et al. ${ }^{49}$ have shown that the scope reprocessing at their institution requires 229.0 \pm 74.4 minutes. At this pace, a reusable ureteroscope used in the first patient of the day would not be ready until the third or fourth case of the day, demanding the institution to have ate least three or four scopes to adequately run the flexible ureteroscopy program. This is a problem one would not face if dealing only with single-use scopes. However, in the clinical study by Doizi et al. ${ }^{17}$, two failures occurred with the disposable scope and in those cases the reusable device allow the case to be finished. This highlights the importance of having a backup scope (single-use or not) if the Institution chooses to follow a routine use of disposable flexible scopes.

Surgical skills evolve with practice and residency training is an important aspect to consider when evaluating which flexible ureteroscope to acquire. A single study suggests that learning curve is shorter with the disposable digital scope though it was not specifically design for that purpose $^{10}$. For that reason, the purchase of a single-use flexible ureteroscope might be considered in training centers. One important manufacturing characteristic is that LithoVue ${ }^{\mathrm{TM}}$ may be continuously used for only 200 minutes if the power cable is kept plugged during all this time period. However, when unplugged from its monitor, the time stops counting and the scope may have prolonged longevity if used in an interrupted manner. This is relevant information if a laboratory for hands on training is part of the institutional plan.

In terms of scope instrumentation and surgical technique, the use of a ureteral access sheath was thought to aid in prolonging scope longevity ${ }^{53-56}$. However, there are no well-designed prospective randomized trials to provide strong evidence that the durability of the deflection unit of the flexible ureteroscope is preserved using this technique and this should be further investigated. On the other hand, previous studies strongly suggest that there is increased damage to the flexible scope if the patient has a urothelial tumor in the lower pole, a staghorn stone, a stone in the lower pole with more than $10 \mathrm{~mm}$, if the lower pole infundibulum is narrow, and if the infundibulopelvic angle is lower than $<30$ to $50^{\circ 48,50-52}$. In those situations, a single-use device could be more cost-effective than using a reusable scope.

This study allowed us to perform an extensive review of published literature concerning flexible ureteroscope financial aspects. We have initially formulated questions to comprehensively evaluate all factors influencing flexible ureteroscope longevity and costs. Notably, none of the authors of trials investigating the financial aspect of flexible ureteroscopy have accounted for the differences of operating room time for digital versus fiberoptic scopes ${ }^{11,42,51,52}$. Also, they did not consider buying new reusable scopes instead of repairing the broken ones. Finally, it is important to highlight that no study has ever considered that for use of a permanent ureteroscope, a video tower with an adequate monitor, camera system and light generator should be available in the operating room. For the single-use scope, this is optional since the manufacturer always bring a dedicated video system that was designed to work integrated with the disposable scope. It is important to highlight that we are not considering the time for reprocessing and its impact in the need of having more than one scope to allow sequential surgeries without 
delaying the next procedures to be performed after the first one is finished.

Our study has some minuses. First, it is a review of existing previous studies and only four prospective randomized trials were considered suitable for this analysis. There is a paucity of well-designed trials concerning flexible ureteroscopy and cost-effectiveness of the procedure, thought it has large application worldwide. A second point, we have not addressed the patient perspective since it does not influence the economic aspect of the process as long as acceptable surgical outcomes are respected. Nevertheless, we must not forget that in several health care policies, the patients are the ones who are actually paying for all the expenditures involved. Third, we did not evaluate disposable materials as they may vary according to surgeon preference, institution policy, and ultimately would not influence the flexible ureteroscope price. Nevertheless, if the institution negotiates an exclusivity contract with a manufacturer of disposables instruments and this company also owns a single-use flexible scope patent, this might be brought to the negotiation with a lower price than of regular market. Finally, we did not study the environmental impact of using disposable devices instead of reusable scopes. Yet, a recent analysis by Davis et al. ${ }^{68}$ has shown that the total carbon footprint of the lifecycle assessment of the LithoVue ${ }^{\mathrm{TM}}$ and reusable scope are not derisive and very similar, $4.43 \mathrm{~kg}$ of $\mathrm{CO} 2$ and $4.47 \mathrm{~kg}$ of $\mathrm{CO} 2$ per case, respectively.

\section{CONCLUSION}

The cost-effectiveness of a flexible ureteroscopy program is dependent of several aspects that must be considered when deciding whether to choose between a single-use and a reusable ureterorenoscope. Disposable devices are already a reality and will progressively become the standard as manufacturing price falls to a point in which the above-mentioned formula will lose its reason to be. The potential benefit of avoiding urothelial tumor spreading and cross-infections due to sterilization failure are yet to be proven. After extensive literature review, considering the actual clinical and economic scenario, we may recommend using the last-generation, digital and high performance single-use scopes in cases of high risk for ureteroscope damage, e.g. large lower pole stone or pathology, cases in which the ureteral access sheath fails to deploy or is not intended (dusting technique), and large stone burden irrespective of location in the kidney. Also, when the market price of purchasing a new scope is elevated, or if ureteroscope repair price is high, migrating to single-use devices might be more cost-effective. In addition, academic centers may find a place for single-use devices in handson courses ad residency training. Finally, no instrument is failure-proof and a back-up device, single-use or not, should always be available in case a second scope is required to finish the case.

\section{REFERENCES}

1. Rouprêt M, Babjuk M, Compêrat E, et al. European Association of Urology Guidelines on Upper Urinary Tract Urothelial Cell Carcinoma: 2015 update. Eur Urol. 2015; 68:868-79. doi: 10.1016/j.eururo.2015.06.044.

2. Turk C, Petrik A, Sarica K, et al. EAU Guidelines on Interventional Treatment for Urolithiasis. Eur Urol. 2016;69:475-82. doi: 10.1016/j.eururo.2015.07.041.

3. Assimos D, Krambeck A, Miller NL, Monga M, Murad MH, Nelson CP, Pace KT, Pais VM Jr, Pearle MS, Preminger GM, Razvi H, Shah O, Matlaga BR. Surgical Management of Stones: American Urological Association/Endourological Society Guideline, Part I. J Urol. 2016;196(4):1153-60. doi: 10.1016/j.juro.2016.05.090.

4. Assimos D, Krambeck A, Miller NL, Monga M, Murad MH, Nelson CP, Pace KT, Pais VM Jr, Pearle MS, Preminger GM, Razvi H, Shah O, Matlaga BR. Surgical Management of Stones: American Urological Association/Endourological Society Guideline, Part II. J Urol. 2016;196(4):1161-9. doi: 10.1016/j.juro.2016.05.091.

5. Somani BK, Al-Qahtani SM, de Medina SD, et al. Outcomes of flexible ureterorenoscopy and laser fragmentation for renal stones: Comparison between digital and conventional ureteroscope. Urology. 2013;82:1017-9. doi: 10.1016/j. urology.2013.07.017.

6. Davis NF, Quinlan MR, Browne C, Bhatt NR, Manecksha RP, D'Arcy FT, Lawrentschuk N, Bolton DM. Single-use flexible ureteropyeloscopy: a systematic review. World J Urol. 2018;36(4):529-36. doi: 10.1007/s00345-017-2131-4.

7. Emiliani E, Traxer O. Single use and disposable flexible ureteroscopes. Curr Opin Urol. 2017;27(2):176-81. doi: 10.1097/MOU.0000000000000371.

8. Bader MJ, Gratzke C, Walther S, Schlenker B, Tilki D, Hocaoglu Y, et al. The PolyScope: a modular design, semidisposable flexible ureterorenoscope system. J Endourol. 2010;24(7):1061-6. doi: 10.1089/end.2010.0077.

9. Ding J, Xu D, Cao Q, Huang T, Zhu Y, Huang K, et al. Comparing the efficacy of a multimodular flexible ureteroscope with its conventional counterpart in the management of renal stones. Urology. 2015;86(2):224-9. doi: 10.1016/j.urology.2015.04.018.

10. Usawachintachit $\mathrm{M}$, Isaacson DS, Taguchi $\mathrm{K}$, Tzou DT, Hsi RS, Sherer BA, et al. A prospective case-control study comparing LithoVue, a single-use, flexible disposable ureteroscope, with flexible, reusable fiber-optic ureteroscopes. J Endourol. 2017; 31(5):468-75. doi: 10.1089/end.2017.0027.

11. Mager R, Kurosch M, Höfner T, Frees S, Haferkamp A, Neisius A. Clinical outcomes and costs of reusable and single-use flexible ureterorenoscopes: a prospective cohort study. Urolithiasis. 2018. doi: 10.1007/s00240-018-1042-1.

12. Alezra E, Lasselin J, Forzini T, Francois T, Viart L, Saint F. Prognostic factors for severe infection after flexible ureteroscopy: Clinical interest of urine culture the day before surgery? Prog Urol. 2016;26(1):65-71. doi: 10.1016/j. purol.2015.09.008.

13. Taguchi K, Usawachintachit M Tzou DT, Sherer BA, Metzler I, Isaacson D, Stoller ML, Chi T. Micro-Costing Analysis Demonstrates Comparable Costs for LithoVue Compared to Reusable Flexible Fiberoptic Ureteroscopes. J Endourol. 2018;32(4):267-273. doi: 10.1089/end.2017.0523.

14. Boylu U, Oommen M, Thomas R, Lee BR. In vitro comparison 
of a disposable flexible ureteroscope and conventional flexible ureteroscopes. J Urol. 2009;182(5):2347-51. doi: 10.1016/j. juro.2009.07.031.

15. Gu SP, Huang YT, You ZY, Zhou X, Lu YJ, He CH, Qi J. Clinical effectiveness of the PolyScope ${ }^{\mathrm{TM}}$ endoscope system combined with holmium laser lithotripsy in the treatment of upper urinary calculi with a diameter of less than $2 \mathrm{~cm}$. Exp Ther Med. 2013;6(2):591-5

16. Bansal H, Swain S, Sharma GK, Mathanya M, Trivedi S, Dwivedi US, et al. Polyscope: a new era in flexible ureterorenoscopy. J Endourol. 2011;25(2):317-21. doi: 10.1089/end.2009.0584.

17.Doizi S, Kamphuis G, Giusti G, Andreassen KH, Knoll T, Osther PJ, et al. First clinical evaluation of a new single-use flexible ureteroscope (LithoVueTM): a European prospective multicentric feasibility study. World J Urol. 2017;35(5):80918. doi: 10.1007/s00345-016-1936-x.

18. Proietti S, Dragos L, Molina W, Doizi S, Giusti G, Traxer O. Comparison of new single-use digital flexible ureteroscope versus nondisposable fiber optic and digital ureteroscope in a cadaveric model. J Endourol. 2016;30(6):655-9. doi: 10.1089/ end.2016.0051.

19. Wiseman O, Keeley F, Traxer O, Giusti G, Lipkin M, Preminger G. Comparison of a new single-use digital flexible ureteroscope (LithoVue) to a non-disposable fibre-optic flexible ureteroscope in a live porcine model. J Urol. 2016;195(4):e682. Doi: https://doi.org/10.1016/j. juro.2016.02.458

20. Dale J, Kaplan AG, Radvak D, Shin R, Ackerman A, Chen T, Scales CD Jr, Ferrandino MN, Simmons WN, Preminger GM, Lipkin ME. Evaluation of a novel single-use flexible ureteroscope. J Endourol. 2017. doi: 10.1089/end.2016.0237.

21. Johnson MT, Khemees TA, Knudsen BE. Resilience of disposable endoscope optical fiber properties after repeat sterilization. J Endourol. 2013;27(1):71-4. doi: 10.1089/ end.2012.0323.

22. Ghodoussipour S, Thompson E, Shah A, Mitra A, Deshmukh S, Dunn M. Mp50-08 Limitations of the lithovue single use digital flexible ureteroscope. J Urol. 2017;197(4):e686-e687. https://doi.org/10.1016/j.juro.2017.02.1596.

23. Marchini GS, Batagello CA, Monga M, Torricelli FCM, Vicentini FC, Danilovic A, Srougi M, Nahas WC, Mazzucchi E. In vitro evaluation of single-use digital flexible ureteroscopes: a practical comparison for a patient-centered approach. J Endourol. 2018; r;32(3):184-191. doi: 10.1089/end.2017.0785.

24. Tom WR, Wollin DA, Jiang R, Radvak D, Simmons WN, Preminger GM, Lipkin ME. Next-generation singleuse ureteroscopes: an in vitro comparison. J Endourol. 2017;31(12):1301-6. doi: 10.1089/end.2017.0447.

25. Multescu R, Geavlete B, Georgescu D, Geavlete P. Improved durability of flex-Xc digital flexible ureteroscope: how long can you expect it to last? Urology. 2014;84(1):32-5. doi: 10.1016/j.urology.2014.01.021.

26. Afane JS, Olweny EO, Bercowsky E, et al. Flexible ureteroscopes: a single center evaluation of the durability and function of the new endoscopes smaller than 9Fr. J Urol. 2000;164(4):1164-8. https://doi.org/10.1016/S00225347(05)67133-9.

27. Karaolides T, Bach C, Kachrilas S, Goyal A, Masood J, Buchholz N. Improving the durability of digital flexible ureteroscopes. Urology. 2013;81(4):717-22. doi: 10.1016/j. urology.2013.01.016.
28. Legemate JD, Kamphuis GM, Freund JE, Baard J, Zanetti SP, Catellani M, Oussoren HW, de la Rosette JJ. Durability of flexible ureteroscopes: a prospective evaluation of longevity, the factors that affect it, and damage mechanisms. Eur Urol Focus. 2018: pii: S2405-4569(18)30079-8. doi: 10.1016/j. euf.2018.03.001.

29. Carey RI, Gomez CS, Maurici G, Lynne CM, Leveillee RJ, Bird VG. Frequency of ureteroscope damage seen at a tertiary care center. J Urol. 2006;176(2):607-10. doi: 10.1016/j. juro.2006.03.059.

30. Monga M, Best S, Venkatesh R, Ames C, Lee C, Kuskowski M, Schwartz S, Vanlangendock R, Skenazy J, Landman J. Durability of flexible ureteroscopes: a randomized, prospective study. J Urol. 2006;176(1):137-41. doi: 10.1016/S00225347(06)00575-1.

31. Traxer O, Dusboq F, Jamali K, et al. New-generation flexible ureterorenoscopes are more durable than previous ones. Urology. 2006;68:276-9. doi: 10.1016/j.urology.2006.02.043.

32. Defidio L, De Dominicis M, Di Gianfrancesco L, et al. Improving flexible ureteroscope durability up to 100 procedures. J Endourol. 2012;26:1329-34. doi: 10.1089/ end.2012.0178

33. Knudsen B, Miyaoka R, Shah K, et al. Durability of the nextgeneration flexible fiberoptic ureteroscopes: A randomized prospective multi-institutional clinical trial. Urology. 2010;75:534-8. doi: 10.1016/j.urology.2009.06.093

34. Siu JJ-Y, Chen H-Y, Liao P-C, Chiang J-H, Chang C-H, Chen Y-H, et al. The cost-effectiveness of treatment modalities for ureteral stones. Inq J Heal Care Organ Provis Financ. 2016;53(91):4695801666901. doi: $10.1177 / 0046958016669015$.

35. Binbay M, Yuruk E, Akman T, Ozgor F, Seyrek M, Ozkuvanci U, Berberoglu Y, Muslumanoglu AY. Is there a difference in outcomes between digital and fiberoptic flexible ureterorenoscopy procedures? J Endourol. 2010;24(12):192934. doi: 10.1089/end.2010.0211

36. Carey RI, Martin CJ, Knego JR. Prospective evaluation of refurbished flexible ureteroscope durability seen in a large public tertiary care center with multiple surgeons. Urology. 2014;84(1):42-5. doi: 10.1016/j.urology.2014.01.022.

37. Collins JW, Keeley FX Jr, Timoney A. Cost analysis of flexible ureterorenoscopy. BJU Int. 2004;93(7):1023-6. doi: 10.1111/j.1464-410X.2003.04774.x.

38. Shah K, Monga M, Knudsen B. Prospective randomized trial comparing 2 flexible digital ureteroscopes: ACMI/ olympus invisio DUR-D and olympus URF-V. Urology. 2015;85(6):1267-71. doi: 10.1016/j.urology.2014.12.012.

39. User HM, Hua V, Blunt LW, Wambi C, Gonzalez CM, Nadler RB. Performance and durability of leading flexible ureteroscopes. J Endourol. 2004;18(8):735-8. doi: 10.1089/ end.2004.18.735.

40. Abraham JB, Abdelshehid CS, Lee HJ, et al. Effects of Steris 1 sterilization and Cidex high level disinfection on durability of new-generation flexible ureteroscopes. J Endourol. 2007;21:985-92. doi: 10.1089/end.2007.0181.

41. Gurbuz C, Atış G, Arikan O, Efilioglu O, Yıldırım A, Danacıoglu $\mathrm{O}$, Caskurlu T. The cost analysis of flexible ureteroscopic lithotripsy in 302 cases. Urolithiasis. 2014;42(2):155-8. doi: 10.1007/s00240-013-0628-x.

42. Martin CJ, McAdams SB, Abdul-Muhsin H, Lim VM, Nunez-Nateras R, Tyson MD, Humphreys MR. The economic implications of a reusable flexible digital ureteroscope: a 
cost-benefit analysis. J Urol. 2017;197(3 Pt 1):730-5. doi: 10.1016/j.juro.2016.09.085.

43. Landman J, Lee DI, Lee C, Monga M. Evaluation of overall costs of currently available small flexible ureteroscopes. Urology. 2003;62(2):218-22. https://doi.org/10.1016/S00904295(03)00376-5.

44. Somani BK, Robertson A, Kata SG. Decreasing the cost of flexible ureterorenoscopic procedures. Urology. 2011; 78(3):528-30. doi: 10.1016/j.urology.2010.12.073.

45. Semins MJ, George S, Allaf ME, et al. Ureteroscope Cleaning and sterilization by the urology operating room team: the effect on repair costs. J. Endourol. 2009;23:903-5. doi: 10.1089/ end.2008.0489.

46. Kramolowsky E, McDowell Z, Moore B, et al. Cost analysis of flexible ureteroscope repairs: evaluation of 655 procedures in a community-based practice. J. Endourol. 2016;30:254-6. doi: 10.1089/end.2015.0642.

47. Tosoian JJ, Ludwig W, Sopko N, et al. The effect of repair costs on the profitability of a ureteroscopy program. J. Endourol. 2015;29:406-9. doi: 10.1089/end.2014.0435.

48. McDougall EM, Alberts G, Deal KJ, Nagy JM III. Does the cleaning technique influence the durability of the $<9 \mathrm{~F}$ flexible ureteroscope? J Endourol. 2001;15:615-8. doi: $10.1089 / 089277901750426409$.

49. Isaacson D, Ahmad T, Metzler I, Tzou DT, Taguchi K, Usawachintachit M, Zetumer S, Sherer B, Stoller M, Chi T. Defining the costs of reusable flexible ureteroscope reprocessing using time-driven activity-based costing. J Endourol. 2017;31(10):1026-31. doi: 10.1089/end.2017.0463.

50. Forbes CM, Rebullar KA, Teichman JMH. Comparison of flexible ureteroscopy damage rates for lower pole renal stones by laser fiber type. Lasers Surg Med. 2018 Mar 31. doi: 10.1002/1sm.22822.

51. Ozimek T, Schneider MH, Hupe MC, Wiessmeyer JR, Cordes J, Chlosta PL, Merseburger AS, Kramer MW. Retrospective cost analysis of a single-center reusable flexible ureterorenoscopy program: a comparative cost simulation of disposable fURS as an alternative. J Endourol. 2017;31(12):1226-30. doi: 10.1089/ end.2017.0427.

52. Hennessey DB, Fojecki G, Papa N, Lawrentschuk N, Bolton D. Single use disposable digital flexible ureteroscopes: an exvivo assessment and cost analysis. BJU Int. 2018;121 Suppl 3:55-61. doi: 10.1111/bju.14235.

53. Stern JM, Yiee J, Park S. Safety and efficacy of ureteral access sheaths. J Endourol. 2000;21:119-23. doi: 10.1089/ end.2007.9997.

54. Berquet G, Prunel P, Verhoest G, et al. The use of a ureteral access sheath does not improve stone-free rate after ureteroscopy for upper urinary tract stones. World J Urol. 2014;32:229-32. doi: 10.1007/s00345-013-1181-5.

55. Pietrow PK, Auge BK, Delvecchio FC, Silverstein AD, Weizer AZ, Albala DM, Preminger GM. Techniques to maximize flexible ureteroscope longevity. Urology. 2002;60:784-8. https://doi.org/10.1016/S0090-4295(02)01948-9.
56. Kourambas J, Byrne RR, Preminger GM. Does a ureteral access sheath facilitate ureteroscopy? J Urol. 2001;165(3):78993. https://doi.org/10.1016/S0022-5347(05)66527-5.

57.Jacquemet B, Martin L, Pastori J, Bailly V, Guichard G, Bernardini S, Chabannes E, Bittard H, Kleinclauss F. Comparison of the efficacy and morbidity of flexible ureterorenoscopy for lower pole stones compared with other renal locations. J Endourol. 2014;28(10):1183-7. doi: 10.1089/ end.2014.0286.

58. Jessen JP, Honeck P, Knoll T, Wendt-Nordahl G. Flexible ureterorenoscopy for lower pole stones: influence of the collecting system's anatomy. J Endourol. 2014;28:146-51. doi: 10.1089/end.2013.0401.

59.Perlmutter AE, Talug C, Tarry WF, Zaslau S, Mohseni H, Kandzari SJ. Impact of stone location on success rates of endoscopic lithotripsy for nephrolithiasis. Urology. 2008;71:214-7. doi: 10.1016/j.urology.2007.09.023.

60. Martin F, Hoarau N, Lebdai S, et al. Impact of lower pole calculi in patients undergoing retrograde intrarenal surgery. J Endourol. 2014;28:141-5. doi: 10.1089/end.2013.0515.

61.Resorlu B, Unsal A, Gulec H, Ozluna D. A new scoring system for predicting stone-free rate after retrograde intrarenal surgery: The "resorlu-unsal stone score". Urology. 2012;80:512-8. doi: 10.1016/j.urology.2012.02.072.

62. Kourambas J, Delvecchio FC, Munver R, et al. Nitinol stone retrieval-assisted ureteroscopic management of lower pole renal calculi. Urology. 2000;56:935-9. https://doi.org/10.1016/ S0090-4295(00)00821-9.

63. Schuster TG, Hollenbeck BK, Faerber GJ, et al. Ureteroscopic treatment of lower pole calculi: comparison of lithotripsy in situ and after displacement. J Urol. 2002;168:43-5. https://doi. org/10.1016/S0022-5347(05)64828-8.

64. White MD, Moran ME. Fatiguability of the latest generation ureteropyeloscopes: Richard Wolf vs. Karl Storz [abstract]. J Endourol. 1998;12(Suppl 1):S182.

65. Bagley DH, Rittenberg MH. Intrarenal dimensions. Guidelines for flexible ureteropyeloscopes. Surg Endosc. 1987;1:119-21.

66. Auge BK, Pietrow PK, Lallas CD, et al. Ureteral access sheath provides protection against elevated renal pressures during routine flexible ureteroscopic stone manipulation. J Endourol. 2004;18:33-6. doi: 10.1089/089277904322836631.

67. Ofstead CL, Heymann OL, Quick MR, Johnson EA, Eiland JE, Wetzler HP. The effectiveness of sterilization for flexible ureteroscopes: a real-world study. Am J Infect Control. 2017;45(8):888-95. doi: 10.1016/j.ajic.2017.03.016.

68. Davis NF, McGrath S, Quinlan M, Jack G, Lawrentschuk N, Bolton DM. Carbon footprint in flexible ureteroscopy: a comparative study on the environmental impact of reusable and single-use ureteroscopes. J Endourol. 2018;32(3):214-7. doi: 10.1089/end.2018.0001.

Submitted for publication: Apr 29, 2018

Accepted in: May 17, 2018 